\title{
An Interview with Susan Bassnett
}

\section{Aditya Kumar Panda}

Susan Bassnett (abridged as SB) holds Professorships of Comparative Literature at the Universities of Glasgow and Warwick. She is an elected Fellow of the Royal Society of Literature, an elected Fellow of the Institute of Linguists and a member of the Academia Europea. Her most recent book, an edited collection of essays on translation and world literature will be published by Routledge later this year. Aditya Kumar Panda (abridged as AKP) interviews Bassnett on the emergence of Translation Studies as a discipline and on the becoming of translation as an interdisciplinary area of studies.

AKP: You established the Department of Comparative Literature at the University of Warwick in your early years at the same university. But your first book is Translation Studies which has seen its fourth edition in 2014. What was the stuff that comparative literature contributed to Translation Studies?

SB: a) I was appointed to the University of Warwick as The Lecturer in Comparative Literature. My task was to set up an MA in Comparative Literature and to teach in the 3 departments of English and Comparative Literary Studies, French and Italian. I duly set up the MA, followed by an MA in Translation Studies and then in British Cultural Studies, and as student numbers increased I was able to set up an independent Graduate School. I always saw translation as fundamental to Comparative Literature (and also to World Literature) so there was never any lack of harmony in building the programmes. 
b) I was lucky enough to meet a small group of people who were dissatisfied with the marginalization of translation in both literary studies and linguistics. They were Itamar EvenZohar, Gideon Toury, Andre Lefevere, Jose Lambert and James Holmes, the key founding figures in Translation Studies. We shared ideas and quickly became friends and at a meeting in Leuven, Belgium in 1976 we decided on the name Translation Studies (coined by James Holmes) to describe what we were trying to develop as a new field of study.

AKP: Basnett is synonymous with Translation Studies now. How did you begin the journey of becoming a scholar in the field of Translation Studies? Your first book also witnesses the same. One could say that Translation Studies visibly started with this book, as there was no such book before. You named the book also as Translation Studies.

SB: In 1977 the late Terence Hawkes had started to edit a pioneering series of books entitled New Accents. The objective was to introduce readers to the bewildering array of new critical approaches that were sweeping through the Humanities in the 1970s and 1980s- semiotics, narratology, feminist criticism, deconstruction, post-structuralism, post colonialism, etc. I managed to persuade him that there should be a book on a new field called Translation Studies. The first edition in 1980 was hailed by the late Bernard Bergonzi as one of his choices for Book of the Year in the Observer newspaper, but it took another decade for the book to begin its successful rise ( 4 subsequent revised editions, translated into over a dozen languages and one of the most cited books on translation ).The New Accents series was a phenomenal 
success and I believe has sold well over half a million copies world-wide. There is a whole chapter on how Translation Studies came into being in my other Routledge book, Translation, published in 2013 in the New Critical Idiom series.

AKP: Translation of literary text is not a skill but an effective rewriting. You had mentioned this in an interview. Don't you think that rewriting is also a skill? Can rewriting be called a translation? Is there any boundary to define translation?

SB: I am of the view that translation is ALWAYS rewriting as no 2 languages and no 2 texts are identical. Translation is the result of one person's reading of a text and then recreating it (that is, rewriting) in another language. It is important to remember that translation is subjective, that no 2 individuals will produce an identical version of anything. Of course rewriting is a skill- how could it not be?

AKP: We are living in a time when various categories are being minimized. We are crossing the boundary of category. With the passage of time, we are moving towards a cosmopolitan world where we are also trying to produce literature which can be considered as world literature. What could be the role of translation here?

SB: I do not understand the question about categories being minimized. Cultures change all the time; hence aesthetics and ideologies are forever in movement. Translation Studies was a very marginal subject until the 1990s, when it suddenly became super fashionable around the world. Why? the answer surely lies in the massive socio-political changes that 
began in 1989 with the fall of the Berlin Wall, the end of the Soviet Union, China opening up to the West, then the end of apartheid... all these events enabled millions of people to begin to move around the planet and so translation and intercultural competencies started to become more significant.

AKP: We are crossing the border. Translator is a traveler. As Michael Cronin in his book "Across the Lines: travel, language, translation" emphasizes on translator as a traveler, someone engaged in a journey from one source to another. The twenty-first century surely promises to be the great age of travel, not only across space but also across time. Translation is becoming a part of inter-cultural relationship. In 21 st century, it is causing negotiation not only between two cultures but more than two cultures and times. One could say that a history of translation is a history of cultural transformation. How would you respond to this?

SB: From the outset, we were all of the view that a key element in Translation Studies should be the history of translation in different cultural contexts. Literary histories have tended to marginalize translation, whereas I see translation as absolutely crucial in the movement of texts across border of language, culture and time. When you have a map of the history of translation in literature, it becomes possible to understand far, far more than if you simply take a narrow nationalist focus.

AKP: Is there any translation theory that can be considered as the theory of translation applicable across language and culture? 
SB: If I understand your question you are seeking some sort of universalizing theory, there is no such thing. The closest we can come is the Sapir-Whorf hypothesis about the relativity of languages and cultures- 'No two languages are ever sufficiently similar to be considered as representing the same social reality. The worlds in which different societies live are distinct worlds, not merely the same world with different labels attached."

AKP: In the preface to the third edition of your book Translation Studies, you have mentioned that in the early years, Translation Studies advocates positioned themselves against both linguists and literary scholars, arguing that "linguists failed to take into account broader contextual dimensions and that literary scholars were obsessed with making pointless evaluative judgments" which gave a way to Translation Studies to come out of its own and it should not be under Comparative Literature and Applied Linguistics. Could you please elaborate this point?

SB: In the early meetings of the Translation Studies group (sometimes known as the Polysystems group, also the Manipulation School) we could see that linguistics tended to downplay contextual issues, also the socio-political aspects of languages. Literary Studies on the other hand was concerned to establish roots and origins for national literatures, and translation was derided as second-class derivative work, not as creative work at all. To some extent that view is still around and has to be constantly challenged so as to assert the crucial importance of translation in literary history and in all our activities. 
AKP: What should be the object of study for a translation theorist? Is it the target text as the Skopos theory puts forth? Is it equivalence or the source text as has been the case traditionally? Is it the translation norm as Toury perceives? Is it the culture as the polysystem scholars like Zohar and postcolonial scholars Bhaba, Spivak study?

SB: The object of study is multifaceted. Attention must be paid to the production of a translation: both the micro-systemic (stylistic features, lexicon, and translator's choices) together with the macro-systemic (the various agents in the translation process- funders, publishers, copy-editors, marketers etc). And it should never be forgotten that texts come into being in a specific cultural context. So we need to look at the contexts in which the source text is produced, the translation is produced and the translation is then received.

AKP: Your book Constructing Cultures: Essays on Literary Translation came out in 1998, now in 2016 tell us where are we in Translation Studies? You have introduced a new concept called "Collusion" in this book? Could you please tell something about this concept?

SB: I used the word 'collusion' first in relation to travel writing, where we the readers take at face value the traveller's account of his/her experiences, conversations, perceptions of another culture. I have a special interest in travel writing, because it is a genre where fact and fiction blur, and we collude in letting go of our common sense as for example, when a writer tells us of amazing conversations with locals in half a dozen different countries when it is clear that the writer has no linguistic competence in those languages and dialects. 
So it is with translations- we collude with the idea that we are somehow actually reading Tolstoy when we are given a translation of one of his novels, for example, whereas what we are actually reading is the rewritten version produced by a translator.

AKP: You don't seem to agree with the notion of performability espounded by many scholars that they find a kind of universal performability inherit in the text, what is the danger in such universalizing concept?

SB: "Performability' is a very vague term. It is often used when talking about theatre texts to suggest that there is some inherent component that enables actors to perform. Some have referred to 'speakability'. My objections to the term are

a. it is not defined, nor is it definable- where exactly can we see it in a play text? is it semantic? rhythmical?

b. If it exists, why do different actors perform such texts so differently?

c. How can such a vague concept be translated? if it cannot be identified as a textual component, what is a translator supposed to do?

d. Different cultures have completely different acting traditions, so how could there ever be a universalizing notion of performability?

To sum up, I view translation as enormously important, and I believe, as Bella Brodzki has suggested in her 2007 book, that translation, like gender, is present in all cultural 
transactions. The research project I directed which led to the monograph with Esperanza Bielsa on translation and global news in 2009 showed the dangers of underestimating the power of translation in our multimedia, fast-moving globalized world, which added a new dimension to my thinking about why translation is so important. 